Sherwood's translation of Mendel's paper on peas is closer to Mendel's German than the RHS translation. This has meant that there are many slight differences between the two versions. For instance, "seed-dealers" instead of " seedsmen ", " estimable" instead of "valuable", " trait" instead of " character". Such exactitudes could surely have been sacrificed so that the two versions would not differ more than is absolutely necessary for the sense of the original. Where the sense has been lost Sherwood has restored it, as in the important conclusion to the section "The Second Generation from Hybrids". She has also avoided confusing wrinkled (runzlig) with angular (kantig); though how wise it was to alter so well known a term may be open to question, especially since both are due to the same cause, i.e. type and amount of starch grains. These examples show that her translation has been prepared with great care and expertise, is thoroughly reliable, but in numerous places its departure from the RHS translation is trivial.

The excellent translations of Mendel's letters to Nägeli and the " rediscovery" papers which the Piternicks prepared for Genetics in 1950 are fortunately included in this volume. Stern and Sherwood have also translated the passages from Focke's book, Die Pflanzenmischlinge, which refer to Mendel, and Evelyn Stern has translated de Vries' report of 1900 to the German Botanical Society. As the first published translation the latter is particularly welcome.

This collection of papers and letters gives a balanced view of Mendel's work and of its rediscovery. The choice of de Vries' German report in place of his much shorter French report is to be commended. Welcome too is Sewell Wright's criticism of Fisher's analysis of Mendel's experiments. In preparing this book Stern and Sherwood have performed a valuable service, for hitherto this material has been available only in scattered sources and some of it only in German.

R. C. OLBY
Dept. of Botany, South Parks Road, Oxford

\title{
THE EXPLOITATION OF PUBLIC RECORDS
}

MONOGRAPHS IN HUMAN GENETICS. Vol. 3: GENETICS OF INTERRACIAL CROSSES IN HAWAll. Newton E. Morton, Chin S. Chung, and Ming-Pi Mi. S. Karger Ag Basel, New York. 1967. Pp. viii $+42+5$ figs. sFR. 39.50 .

In human genetics we are now faced with the situation in which, due to genetic variability in man usually being expressed either very strongly, or weakly, two fundamentally different approaches in data collection and analysis are needed. Strong effects are being adequately studied by the aid of simple genetic models in agglutination tubes, electrophoretic gels, and hospital wards. However, the greater part of human variability, both in health and disease, appears to be due to the weak effects which seem invulnerable to the erratic collections of ancestral data which, for want of better, are often recommended in the study of common disorders, particularly those affecting the foetus, and which are now being widely collected in various genetic clinics which are being set up on the assumption that manually collected pedigrees are necessarily useful.

To attack these more confusing problems of common variation which 
are not amenable to single factor models we need statistical concepts and large numbers, and, for want of better, have to make do with such records as are available, through our entrances and exits, supplemented by records of various intervening events, such as hospital admission, blood group and occupation. The vast expense of assembling and analysing such data, although trivial compared to the cost already spent on their initial collection, should impose an obligation on both research workers and their patrons to make the data available to others. This would seem an obvious moral need in human data, particularly now that the computer has made this simple, but few authors practice it, and few patrons demand it, in spite of the obvious fact, which has been repeatedly demonstrated at public expense, that those who are most industrious at collecting data often have little idea of what to do with them.

This book is a landmark in the exploitation of public records; Hawaii has good records, a known history, numerous races, both Atlantic and Pacific, a geneticist responsible for major theoretical advances in the specifying and estimating some relevant parameters, and adequate computing facilities. The genetics department itself is better equipped than many British Universities.

The data are introduced, with full details of ascertainment and coding. The authors exploit it, primarily by variance partitioning methods, and the sifting out of significant effects, with due regard for sifting fallacies. Nonsignificant associations get little attention. Indeed, they are not even considered worth the cost of type-setting in some tables. Computing loads have been reduced by a sequential procedure of " pre-forced" variables, which is poorly explained, and the bias of selecting significant effects is not considered. The primary aim, the estimation of the effects of interracial crosses, has been answered conclusively: Hawaii is too small to show them. The final chapter is a particularly valuable summary of the authors' view and greatly clarifies the earlier work on loads by the senior author.

A most important comment, on page 38, states that "The authors will endeavour to accommodate researchers wishing to use either the program or the data". Those of us who feel uncomfortable about the assumptions implicit in multiple regression analysis and variance splitting, particularly on observational data, can reasonably be asked to suggest operational alternatives before being too critical.

This book is essential for anyone interested in the population genetics of man, or in the implications of the "load" approach. It is mainly written in the very concise prose style of the senior author. We may hope that, in a few years, sibships will allow an extension of the same basic data to be used for more direct estimates of heritability.

J. H. EDWARD

Dept. of Social Medicine, The Medical School, Edgbaston, Birmingham, 15

\section{CHROMOSOME ABNORMALITIES IN MAN}

MEDICAL CYTOGENETICS. M. Bartalos and Th. A. Baramki. Williams and Wilkins Co., Baltimore; E. and S. Livingstone Ltd., Edinburgh. 1967. $£ 5$.

The first part deals with " general cytogenetics" including technique while the remaining sections consider the phenotypic consequences of chromosome 